\title{
Preconceito Contra Homossexuais e Representações Sociais da Homossexualidade em Seminaristas Católicos e Evangélicos ${ }^{1}$
}

\author{
Cícero Roberto Pereira ${ }^{2}$ \\ Instituto de Ciências Sociais da Universidade de Lisboa \\ Ana Raquel Rosas Torres \\ Universidade Federal da Paraíba \\ Annelyse Pereira \\ Instituto Universitário de Lisboa \\ Luciene Campos Falcão \\ Universidade Paulista (Goiânia)
}

\begin{abstract}
RESUMO - Este trabalho analisa as relações entre o preconceito contra os homossexuais e as representações sociais sobre a homossexualidade. Trata-se de um estudo correlacional com 374 estudantes de teologia (207 evangélicos e 167 católicos) que responderam um questionário sobre crenças e atitudes em relação aos homossexuais. Os resultados indicam duas formas de expressão do preconceito: sutil e flagrante. O preconceito sutil está relacionado com a crença numa natureza biológica e psicossocial e com a descrença numa representação ético-moral da homossexualidade. O preconceito flagrante está relacionado com a descrença na natureza biológica e psicossocial e com uma representação ético-moral. A hipótese de que as representações sociais sobre a natureza dos grupos minoritários estão na base do preconceito e da discriminação é corroborada.
\end{abstract}

Palavras-Chave: Preconceito; homofobia; representações sociais

\section{Prejudice against Homosexuals and Social Representations of Homosexuality of Catholic and Evangelic Seminarians}

\begin{abstract}
This study analyzes the relationship between prejudice against homosexuals and social representations about homosexuality. Participants were 374 theology students (167 catholic and 207 evangelic) who individually answered a questionnaire about beliefs and attitudes toward homosexuals. Results allowed to identify two forms of prejudice: Subtle and blatant. The subtle prejudice is related to biological and psychosocial representations about homosexuality and to the disbelief in an ethical and moral nature of homosexuality. The blatant prejudice is related with the disbelief in a biological and psychosocial nature as well as with ethical and moral representations about homosexuality. In the discussion it is argued that social representations about the nature of minority groups can form the basis of prejudice and discrimination.
\end{abstract}

Keywords: prejudice; homophobia; social representations

Os resultados apresentados por diversas linhas de pesquisa têm mostrado que a manifestação explícita do preconceito tem diminuído nas últimas décadas (e.g., Gaertner \& Dovidio, 1986; Katz \& Hass, 1988; McConahay, Hardee \& Batts, 1981; Pettigrew \& Meertens, 1995; Sears \& Henry, 2003). Contudo, empiricamente também se evidencia que essa redução se verifica apenas em relação aos grupos sociais protegidos pela norma do anti-preconceito (e.g., Crandall, Eshleman \& O'Brien, 2002). De fato, contra grupos que não estão protegidos por essas normas, a manifestação flagrante ainda persiste com grande intensidade (e.g., Deschamps,

1 Agradecimentos: Gostaríamos de expressar os nossos mais sinceros agradecimentos aos diretores dos seminários que muito gentilmente abriram as portas de suas instituições para que fosse possível a realização deste estudo. Gostaríamos também de agradecer ao doutor Ronaldo Pilati (Universidade de Brasília) e a dois revisores anônimos pelos valiosos comentários e sugestões que fizeram. Também somos gratos a doutora Alice Ramos (Instituto de Ciências Sociais da Universidade de Lisboa) pela leitura atenta que fez dos resultados que aqui apresentamos.

2 Endereço para correspondência: Avenida Professor Aníbal de Bettencourt, 9; 1600-189 Lisboa - Portugal. E-mail: cicero.pereira@ics.ul.pt
Vala, Marinho, Lopes \& Cabecinhas, 2005; Pereira, Vala \& Leyens, 2009; Vala, Lopes, Lima \& Brito, 2002), como o preconceito contra homossexuais (e.g., Frank \& McEneaney, 1999; Lacerda, Pereira \& Camino, 2002; Melton, 1989). Ainda que exista uma representação social amplamente compartilhada de que "todos devem ter direitos iguais perante a Lei", no que se refere às minorias sexuais, a aplicação desse princípio parece ser mais complexa, como têm revelado as investigações sobre o preconceito contra os homossexuais (e.g., Crawford, McLeod, Zamboni \& Jordan, 1999; Faria, Leite, Torres \& Bittar, 2006; Haddock, Zanna \& Esses, 1993; Moradi, van den Berg \& Epting, 2006; Torres \& Faria, 2008).

Contrariamente ao que acontece em grupos protegidos pela norma do anti-preconceito, as manifestações contra a aplicação dos princípios de igualdade aos homossexuais são freqüentes, nomeadamente as organizadas pelos movimentos religiosos. Entretanto, as pesquisas ainda não responderam de forma clara a questões que envolvem a forma como esses grupos religiosos, especialmente os evangélicos e os católicos, expressam o seu posicionamento em relação aos homossexuais e aos mecanismos psicossociais que fundamentam esses posicionamentos. Especificamente indagamos: como 
as pessoas diretamente envolvidas com os cultos religiosos evangélicos ou católicos manifestam as suas atitudes em relação aos homossexuais? Quais são as relações entre essas atitudes e as crenças que esses grupos têm acerca da natureza da homossexualidade? E, finalmente, católicos e evangélicos partilham as mesmas crenças sobre a homossexualidade? Para responder a essas questões, este artigo apresenta um estudo, realizado em seminários católicos e evangélicos, sobre como as atitudes de seminaristas em relação aos homossexuais se relacionam com as representações sociais da natureza da homossexualidade e sobre a ancoragem social dessas representações no tipo de seminário estudado.

\section{Crenças Essencialistas e Representações Sociais sobre a Natureza da Homossexualidade}

Mesmo que a importância das representações sociais para a compreensão do preconceito (e.g., Deschamps et al., 2005; Moscovici \& Pérez, 1997; Pérez, Moscovici \& Chulvi, 2002) já tenha sido sublinhada, pouca atenção tem sido dada a um tipo mais específico de representações - as teorias de senso comum sobre a natureza dos grupos sociais, no tocante às atitudes preconceituosas. No entanto, ainda que não invoque de forma explícita a teoria das representações sociais, os estudos desenvolvidos à luz do conceito de essencialismo psicológico propõem, de uma maneira ou de outra, que as teorias que as pessoas têm sobre a natureza dos grupos sociais são fatores fundamentais para a compreensão das tensões intergrupais. O essencialismo é um processo resultante da crença de que cada categoria de objetos possui um conjunto fixo de características que definem a natureza mais profunda dos elementos das categorias (Medin \& Ortony, 1989). Para Rothbart e Taylor (1992), as pessoas atribuem diferentes essências às categorias naturais e também às categorias sociais, ou seja, os grupos que são socialmente construídos são representadas como espécies biológicas.

A investigação nesse domínio tem analisado a estrutura das crenças essencialistas (e.g., Bastian \& Haslam, 2006; Haslam, Bastian \& Bissett, 2004; Hegarty \& Pratto, 2001) e o seu papel nas atitudes intergrupais (e.g., Haslam \& Levy, 2006; Leyens et al., 2000). Por exemplo, Haslam, Rothschild e Ernst (2000) identificaram dois princípios organizadores das crenças essencializadoras dos grupos sociais: as crenças naturalizantes (os grupos sociais têm uma base biológica imutável); entitatividade (crença em uma similaridade profundamente enraizada entre os membros dos grupos sociais). Relativamente aos homossexuais, Hegarty e Pratto (2001) também identificaram duas dimensões organizadoras destas crenças: a imutabilidade (crença de que a homossexualidade tem base biológica, fixada no início da vida e difícil de mudança) e a fundamentalidade (crença de que os homossexuais são profundamente diferentes dos heterossexuais). Mais recentemente, Haslam e Levy (2006) além da imutabilidade, propuseram mais dois tipos de crenças: a universalidade (crença de que a homossexualidade é histórica e culturalmente determinada) e a separação (crença de que os homossexuais têm características que os distinguem dos heterossexuais).
Esses estudos também mostram que as teorias implícitas que as pessoas têm sobre a natureza dos grupos sociais desempenham um papel importante no preconceito. Por exemplo, Haslam, Rothschild e Ernst (2002) verificaram que as crenças essencializadoras de que a homossexualidade tem base biológica estavam positivamente relacionadas com a atitude pró-homossexuais e, para Hegarty e Pratto (2001) há uma correlação positiva entre a crença na imutabilidade e a atitude anti-gay (ver também Hegarty, 2002) e Haslam e Levy (2006) constataram que a crença na universalidade inibe a atitude negativa em relação à homossexualidade. No entanto, esses estudos procuraram caracterizar apenas as crenças sobre uma natureza quase exclusivamente biológica da homossexualidade (e.g., Jayaratne et al., 2006), dando pouca ou nenhuma atenção a crenças que talvez sejam mais importantes no desenvolvimento do preconceito contra os homossexuais. De fato, a análise das crenças essencialistas não tem levado em consideração as crenças amplamente difundidas no senso comum de que a homossexualidade está relacionada com "tentações demoníacas", com a "fraqueza moral", com as "desordens psicológicas" e com fatores psicossociais, os quais podem ser mais importantes para a caracterização das representações sobre a natureza da homossexualidade do que as crenças relativas a uma essência biológica.

Para podermos analisar de forma mais completa as teorias de senso comum sobre a natureza dos grupos sociais, propomos que as crenças essencialisantes sejam compreendidas no âmbito dos processos descritos por Moscovici (1969/1976) para caracterizar as representações sociais. Especificamente, pressupomos que a essencialização é um exemplo típico dos processos de objetivação, especificamente a ontologização, que explica como as pessoas reificam e naturalizam conceitos e relações científicas, transformando-os em saber de senso comum (ver Jost, 1992), e precisamente, que as dimensões das crenças essencialistas podem ser mais bem compreendidas se analisadas como representações sociais sobre a natureza dos grupos sociais.

Nesta perspectiva, Lacerda et al. (2002) mostraram que as representações sociais da homossexualidade sobre a natureza da homossexualidade são compostas por cinco princípios organizadores (ver também Pereira, Torres \& Pereira, 2003): crença na natureza religiosa (tendência pecaminosa da homossexualidade), crença na natureza ético-moral (que homossexualidade representa a tendência das pessoas para a violação dos valores morais e tradicionais), crença na natureza psicológica (que a homossexualidade tem base psicológica), crença na natureza biológica (que a homossexualidade está relacionada com os fatores hereditários, hormonais e gestacionais) e crença na natureza psicossocial da homossexualidade (que a homossexualidade está relacionada com aspectos identitários e não-essencializantes). A importância dessas representações, segundo Camino e Pereira (2000), é que as teorias e as práticas científicas quando são transformadas em saber de senso comum podem contribuir para o processo de discriminação social contra os homossexuais (ver Crawford et al., 1999, para uma interpretação similar, mas em outra perspectiva). Perguntamos, então, como o preconceito contra os homossexuais é mantido pelas teorias de senso comum? 


\section{Preconceito Contra os Homossexuais e Representações Sociais da Homossexualidade}

Seguindo os resultados de Pettigrew e Meertens (1995) referentes às características do preconceito flagrante e sutil na Europa, Lacerda et al. (2002) identificaram uma tipologia similar em relação à expressão do preconceito contra homossexuais. Lacerda et al. constataram que os preconceituosos flagrantes exprimem rejeição à proximidade e expressam mais emoções negativas do que positivas em relação aos homossexuais. Os preconceituosos sutis exprimem menos rejeição à proximidade e menos emoções negativas do que os preconceituosos flagrantes, mas não expressam mais emoções positivas. Os não- preconceituosos exprimem menos rejeição à proximidade, menos emoções negativas e mais emoções positivas do que os preconceituosos sutis e os flagrantes. Assim, os critérios usados para a análise de outras formas de preconceito, como a proposta por Pettigrew e Meertens (1995) também são úteis para o entendimento do posicionamento das pessoas em relação aos homossexuais (ver também Meertens \& Pettigrew, 1997; Pettigrew et al., 1998; Pettigrew \& Meertens, 2001 e, para uma revisão, ver Vala, Brito \& Lopes, 1999).

Lacerda et al. (2002) também mostraram que os preconceituosos flagrantes compartilham crenças ético-morais e religiosas em relação à homossexualidade. Os preconceituosos sutis recorrem mais a crenças sobre a natureza biológica e psicológicas, ao passo que os não-preconceituosos recorrem a fatores psicossociais. Esses resultados levaram Lacerda et al. a concluírem que as representações sobre a natureza da homossexualidade podem contribuir para a manutenção de práticas discriminatórias, tendo em vista que salientam ou uma representação essencializante do homossexual como portador de alguma anormalidade biológica ou psicológica, ou uma representação do homossexual como portador de uma essência ainda que difusa que o impulsiona para a violação dos valores tradicionais que sustentam o statu quo.

Além disso, a pertença social dos indivíduos ancora as suas representações e o preconceito contra os homossexuais. Por exemplo, os estudantes de engenharia civil foram mais preconceituosos flagrantes, representando a homossexualidade com base em crenças ético-morais e religiosas. Os estudantes de medicina expressaram maior preconceito sutil e recorreram mais a crenças biológicas sobre a homossexualidade. Estudantes de psicologia aparecem de forma mais freqüente no grupo dos não-preconceituosos, adotando crenças sobre a natureza psicossocial da homossexualidade. Os resultados também indicaram que a pertença religiosa (católica versus evangélica) não se relacionava diretamente com o preconceito, embora as crenças religiosas e ético-morais tenham sido centrais na definição do grupo dos preconceituosos flagrantes.

A centralidade dessas crenças torna ainda mais relevante uma investigação mais detalhada sobre as relações entre as representações da homossexualidade e o preconceito contra homossexuais em contextos religiosos. Portanto, apresentaremos a seguir um estudo sobre como as pessoas diretamente envolvidas com os cultos religiosos (seminaristas evangélicos e católicos) manifestam as suas atitudes em relação aos homossexuais, analisando as relações entre essas atitudes e as crenças que esses grupos têm sobre a natureza da homossexualidade e identificando quais são as representações sobre a natureza da homossexualidade praticadas nos dois tipos de seminários.

\section{Método}

\section{Participantes}

Este estudo foi realizado com dados de 374 estudantes de teologia de ambos os sexos, sendo 207 evangélicos e 167 católicos. O estudo foi realizado em vários seminários diocesanos católicos, bem como em vários seminários evangélicos com diferentes orientações teológicas (tradicionais reformados, pentecostais e neo-pentecostais). A maioria dos participantes era do sexo masculino $(78 \%)^{3}$ com idade variando entre 14 a 54 anos $(M=27,7 ; D P=7,51)$. O tempo de seminário variou de 1 a 12 anos $(M=4,1 ; D P=2,46)$. O grau médio de religiosidade era elevado $(M=4,9 \mathrm{com}$ $D P=1,21$ em uma escala em que 1 indica pouco religioso e 7, muito religioso). Os participantes dos dois tipos de seminários diferenciavam-se em todas essas variáveis sócio-demográficas. Os participantes evangélicos tinham idade mais elevada $(M=29,0 ; D P=8,48)$ que os católicos $(M=$ $26,0 ; D P=5,64), t(372)=4,00 ; p<0,001$. Em contrapartida, os católicos tinham maior tempo de seminário $(M=4,7 ; D P$ $=2,59)$ do que os evangélicos $(M=3,7 ; D P=2,26), t(372)$ $=4,02 ; p<0,001$. Os católicos também se consideravam mais religiosos $(M=5,1 ; D P=0,88)$ que os evangélicos $(M=4,8 ; D P=1,42), t(372)=2,23 ; p<0,05$. Portanto, em razão das diferenças sócio-demográficas significativas entre os grupos, essas variáveis foram controladas nas análises realizadas sobre as relações entre as representações sociais e o preconceito contra os homossexuais.

\section{Procedimentos e Medidas}

Seguimos três etapas para a realização do estudo. Inicialmente, fizemos um levantamento dos seminários católicos e evangélicos de uma importante cidade do Centro-Oeste do Brasil. Em seguida, realizamos visitas aos coordenadores desses seminários para a obtenção da autorização formal para efetuar o estudo. Finalmente, aplicamos os questionários que foram respondidos individualmente em salas de aula por todos os estudantes de teologia que se dispuseram a participar da pesquisa. Verificamos apenas $1,5 \%$ de recusas aleatórias (i.e., não relacionadas com o tipo de seminário), as quais não constituem fonte de ameaça à qualidade dos dados obtidos. Usamos um questionário que, além de conter indicadores

3 É rara a presença de mulheres em cursos de teologia católicos. Em seminários evangélicos, a presença de mulheres é mais freqüente. Embora alguns seminários de ambas as denominações permitam a presença de mulheres, elas não estudam para serem líderes religiosas (pastoras ou sacerdotisas). Nos seminários estudados, as mulheres estavam se preparando para assumir funções coadjuvantes: religiosas (freiras) e religiosas-leigas nos seminários católicos; missionárias, nos seminários evangélicos. 
sobre as características sócio-demográficas dos participantes (sexo, idade, tempo de curso e grau de religiosidade), apresentava medidas do preconceito contra os homossexuais e uma medida de crenças sobre a natureza da homossexualidade. Este estudo foi aprovado pelo Comitê de Ética em Pesquisa da Pontifícia Universidade Católica de Goiás.

Medimos o preconceito mediante duas escalas: a) rejeição a relações de proximidade e b) expressão de emoções. A escala de rejeição a relações de proximidade com homossexuais foi desenvolvida e validada por Lacerda et al. (2002). Os participantes indicaram em que medida se sentiram constrangidos no tocante a cada uma das dez situações descritas nos itens da escala (ver também Pereira et al., 2004). As respostas variaram de 1 (nada constrangido) a 7 (muitíssimo constrangido). Aplicamos uma análise fatorial (método dos eixos principais) aos escores obtidos. Apenas um fator foi extraído (cargas fatoriais variando de 0,66 a 0,80 ; valor-próprio $=5,50)$, que explica $55 \%$ da variabilidade. Além disto, essa medida apresentou consistência interna muito elevada $(\alpha=0,92)$, permitindo-nos calcular um índice de rejeição a relações de proximidade no tocante aos homossexuais.

A segunda medida do preconceito (expressão de emoções) também foi validada por Lacerda et al. (2002). A escala contém uma lista com seis emoções, três dessas são positivas e três, negativas. A tarefa dos participantes consistiu em indicar em uma escala de 1 (nunca) a 7 (muitas vezes) o quanto sentiram estas emoções em relação a homossexuais. Os resultados da análise fatorial pelo método dos eixos principais mostraram dois fatores que explicavam $46 \%$ da variabilidade da expressão de emoções. O fator 1 (cargas fatoriais variando de 0,59 a 0,77 ; valor-próprio $=1,54$; variância explicada $=26 \%$ ) explicava $26 \%$ da variabilidade e organizava as emoções negativas. $\mathrm{O}$ fator 2 (cargas fatoriais variando de 0,51 a 0,70 ; valor-próprio $=1,20)$ explicava $20 \%$ da variabilidade e organizava as emoções positivas. A análise da fidedignidade desses fatores mostrou coeficientes alfa suficientes para o cálculo de indicadores consistentes da expressão de emoções negativas e positivas em relação aos homossexuais ( $\alpha=0,75$ e 0,70 , respectivamente).

Também usamos a escala elaborada e validada por Lacerda et al. (2002) para avaliar as representações sociais sobre a natureza da homossexualidade. Esta escala é composta por quinze itens que avaliam cinco tipos de representações: crenças na natureza religiosa, na natureza biológica, na natureza ético-moral, na natureza psicológica e na natureza psicossocial da homossexualidade. A tarefa dos participantes foi indicar o seu grau de concordância em cada item da escala. As respostas podiam variar de 1 (discorda totalmente) a 7 (concorda totalmente). Submetemos as respostas aos itens a uma análise fatorial (método dos eixos principais). Os cinco fatores obtidos explicam $54 \%$ da variância compartilhada. O primeiro fator saturava as crenças religiosas (cargas fatoriais variando de 0,61 a 0,70 ; valor-próprio $=1,90$; variância explicada $=13 \%$ ). O segundo fator organizava as crenças ético-morais (cargas fatoriais variando de 0,43 a 0,85 ; valor-próprio $=1,81$; variância explicada $=12 \%$ ). No terceiro fator, saturam as crenças psicológicas (cargas fatoriais variando de 0,46 a 0,85 ; valor-próprio $=1,67$; variância explicada $=11 \%$ ). No quarto fator, saturaram as crenças biológicas (cargas fatoriais variando de 0,38 a 0,78 ; valor-próprio $=$
1,41; variância explicada $=9 \%$ ). O quinto fator organizava as crenças psicossociais (cargas fatoriais variando de 0,52 a 0,62 ; autovalor $=1,32$; variância explicada $=9 \%$ ). Em seguida, calculamos cinco índices, um para cada tipo de crença, os quais apresentam elevada consistência interna: crenças religiosas $(\alpha=0,82)$, ético-morais $(\alpha=0,81)$, psicológicas $(\alpha=0,73)$, biológicas $(\alpha=0,72)$ e psicossociais $(\alpha=0,69)$.

\section{Resultados}

Orientamos a análise dos dados pelo modelo da análise quantitativa das representações sociais (Doise, Clémence, \& Lorenzi-Cioldi, 1993). Inicialmente, identificamos os tipos de preconceito contra os homossexuais expressos pelos seminaristas. Em seguida, analisamos as relações entre os tipos de preconceito e as representações sobre a natureza da homossexualidade. Por fim, analisamos a ancoragem social dessas representações nos seminários freqüentados pelos participantes.

Para responder à questão referente a como os seminaristas exprimem as suas atitudes em relação aos homossexuais, seguimos os procedimentos realizados por Lacerda et al. (2002) para a identificação do tipo de preconceito que as pessoas expressam contra os homossexuais. Neste sentido, aplicamos a Hierarchical Cluster Analyse para indivíduos (HCA - Análise Hierárquica de Aglomerados; ver Aldenderfer \& Blashfield, 1984) aos escores dos participantes nas escalas de rejeição à proximidade e de expressão de emoções positivas e negativas. Com base no método de Ward (1963) para a construção dos aglomerados, a análise permitiu-nos identificar dois grupos ou clusters de indivíduos, um formado por 267 (72\%) e, o outro, por 104 (28\%) indivíduos.

Para identificarmos os perfis desses grupos, calculamos uma MANOVA tomando os dois grupos definidos na HCA como um fator inter-sujeitos e as medias de adesão às escalas de rejeição à proximidade, emoções positivas e negativas, como variáveis dependentes. Os resultados dessa análise mostram um efeito multivariado significativo, $F(3,367)=$ $247,41, p<0,001$. Esse resultado indica que os perfis dos dois grupos são diferentes no que concerne à expressão do preconceito contra os homossexuais. A classificação dos participantes nesses dois grupos explica $67 \%$ da variância total dos posicionamentos nas escalas utilizadas $(\mathrm{V}=0,67)$. Além disto, todas as diferenças entre os grupos são significativas: $F_{\text {Emoções Negativas }}(1,369)=95,78, p<0,001, \eta^{2}=0,21 ; F_{\text {Emoçoos }}$ Positivas $(1,369)=36,75, p<0,001, \eta^{2}=0,09 ; F_{\text {Rejeição à proximidade }}$ $(1,369)=70,63, p<0,001, \eta^{2}=0,66$. A análise das médias obtidas mostra (Figura 1) que o grupo 1 pode ser chamado de Preconceituoso Flagrante, pois seus participantes são os que mais expressam emoções negativas $(M=2,6, D P=1,42)$, menos emoções positivas $(M=1,5, D P=0,86)$ e maior rejeição à proximidade $(M=5,3, D P=0,98)$. Os membros do grupo 2 podem ser chamados de Preconceituosos Sutis, pois, embora apresentem pouca rejeição a relações de proximidade $(M=2,3, D P=0,86)$ e expressem poucas emoções negativas $(M=1,2, D P=0,42)$, também manifestam poucas emoções positivas $(M=2,2, D P=1,23)$ em relação aos homossexuais. Diferentemente dos resultados encontrados por Lacerda et al. (2002), no presente estudo não identificamos um grupo de 


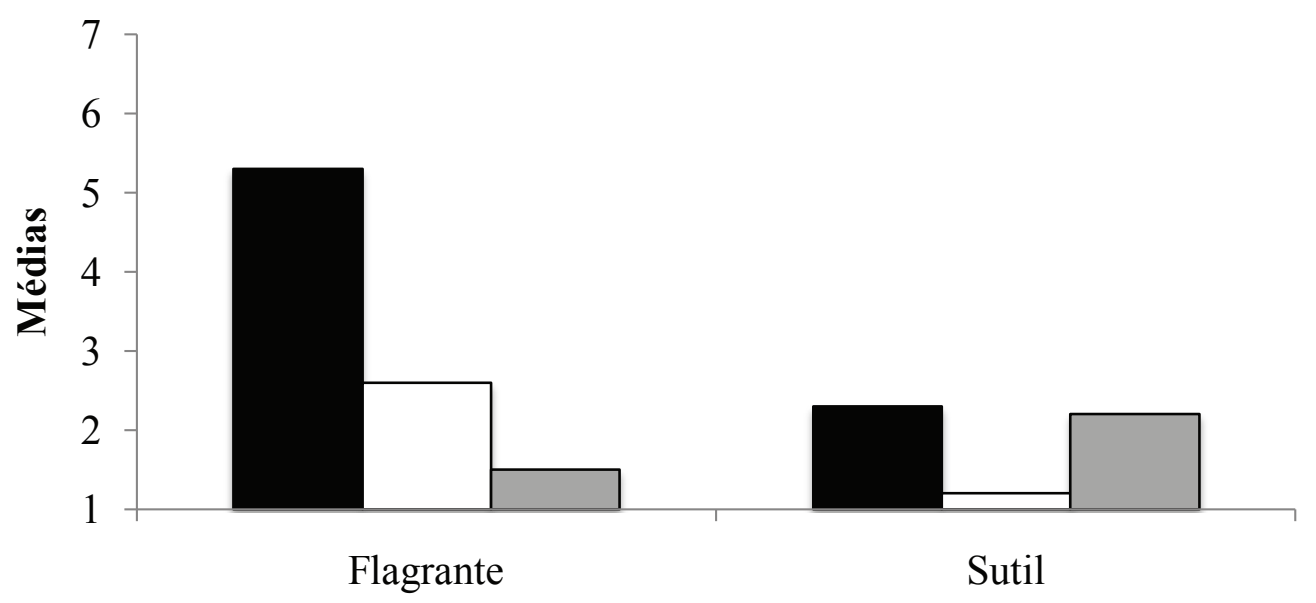

Tipo de Preconceito

\section{- Rejeição à Proximidade $\square$ Emoções Negativas $\square$ Emoções Positivas}

Figura 1. Adesão às escalas do preconceito em função dos grupos (flagrantes vs. sutil) definidos pela Análise Hierárquica de Aglomerados.

indivíduos não-preconceituosos, o qual se caracteriza pela baixa rejeição à proximidade, associada à baixa expressão de emoções negativas e pela alta manifestação de emoções positivas.

\section{Ancoragem do Preconceito}

Após a definição dos dois tipos de preconceito, analisamos como as adesões às cinco crenças sobre a natureza da homossexualidade ancoram esse preconceito, verificada mediante regressões logísticas. Usamos como variáveis critério o tipo de preconceito (Preconceituosos Sutis versus Flagrantes) identificados na HCA e, como variáveis preditoras, as crenças sobre a natureza da homossexualidade (religiosas, ético-morais, psicossociais, psicológicas e biológicas), controlando os efeitos das características sócio-demográficas dos participantes (tipo de seminário, sexo, idade, tempo de curso e grau de religiosidade). Calculamos dois modelos de regressão. No primeiro modelo, estimamos apenas os efeitos das variáveis sócio-demográficas. No segundo modelo, adicionamos as crenças sobre a natureza da homossexualidade. Os resultados do Modelo 1 mostram uma explicação substancial do tipo de preconceito (Nagelkerke $R^{2}=0,29 ; \chi^{2}=70,37 ; p<0,001$ ) o que significa que os dados sócio-demográficos predizem o tipo de preconceito dos participantes. Contudo, a análise dos coeficientes de regressão e dos odds ratios (ver as colunas do Modelo 1 na Tabela 1) indica que o tipo de seminário é a única variável sócio-demográfica que prediz significativamente o tipo de preconceito, de maneira que a participação em seminários evangélicos aumenta mais de doze vezes a probabilidade de os participantes serem classificados como preconceituosos flagrantes, ou seja, os evangélicos são mais flagrantes, ao passo que os católicos são mais sutis. De fato, 69\% dos preconceituosos flagrantes estudam em seminários evangélicos e $84 \%$ dos preconceituosos sutis, em seminários católicos.
Os resultados do Modelo 2 mostram uma predição ainda mais forte do preconceito (Nagelkerke $R^{2}=0,47$; $\left.\chi^{2}=120,52 ; p<0,001\right)$, com incremento substancial na explicação das probabilidades de classificação dos participantes nos dois tipos de preconceito $\left(\Delta R^{2}=0,18\right)$, $\chi^{2}=50,14, p<0,001$, o que significa que a adição das crenças sobre a natureza da homossexualidade melhorou substancialmente a diferenciação entre preconceituosos sutis e flagrantes ${ }^{4}$. A análise dos coeficientes de regressão e dos odds ratios (ver as colunas do Modelo 2 na Tabela 1) indica que o efeito do tipo de seminário continua significativo, e que a pertença a seminários evangélicos aumenta a probabilidade de classificação como preconceituoso flagrante. De maior importância, excetuando os efeitos das crenças religiosas e psicológicas que não são significativos, as relações entre as crenças sobre a natureza da homossexualidade e o tipo de preconceito mostram que, de fato, a forma como seminaristas expressam as suas atitudes em relação aos homossexuais está associada às suas representações sobre a homossexualidade. Já a adesão às crenças ético-morais aumenta a probabilidade de os participantes serem preconceituosos flagrantes, enquanto que a adesão às crenças biológicas e, sobretudo, às psicossociais diminuem a probabilidade de serem flagrantes e, conseqüentemente, aumenta a probabilidade de expressarem o seu preconceito de forma sutil.

4 Análises complementares realizadas dentro de cada tipo de seminário indicam que a tradição religiosa dos seminários não altera o efeito das representações sobre a homossexualidade na expressão do preconceito, i.e., o efeito destas representações mantém-se significativos mesmo quando a denominação do seminário é controlada: $\Delta R^{2}=0,29, \chi^{2}=$ $24,02, p<0,001$, nos seminários protestantes; $\Delta R^{2}=0,23, \chi^{2}=29,59$, $p<0,001$, nos seminários católicos. 
Tabela 1. Parâmetros estimados nos modelos de regressões logísticas para a análise dos preditores do preconceito (sutil vs. flagrante) contra os homossexuais

\begin{tabular}{|c|c|c|c|c|c|c|}
\hline \multirow{2}{*}{ Preditores } & \multicolumn{3}{|c|}{ Modelo 1} & \multicolumn{3}{|c|}{ Modelo 2} \\
\hline & $\mathrm{B}$ & $O R$ & $\mathrm{IC}(95 \%)$ & $\mathrm{B}$ & $O R$ & $\mathrm{IC}(95 \%)$ \\
\hline \multicolumn{7}{|l|}{ Sócio-demográficas } \\
\hline Seminários & $2,52 * * *$ & 12,43 & $5,72-27,0$ & $1,14^{*}$ & 3,13 & $1,14-8,21$ \\
\hline Sexo & $-0,59$ & 0,56 & $0,22-1,39$ & $-0,21$ & 0,81 & $0,30-2,20$ \\
\hline Idade & $-0,01$ & 0,99 & $0,94-1,04$ & $-0,03$ & 0,98 & $0,92-1,02$ \\
\hline Tempo de Seminário & $-0,06$ & 0,94 & $0,84-1,06$ & $-0,02$ & 0,98 & $0,86-1,12$ \\
\hline Religiosidade & $-0,13$ & 0,88 & $0,66-1,16$ & $-0,13$ & 0,88 & $0,63-1,23$ \\
\hline \multicolumn{7}{|l|}{ Crenças (adicionadas) } \\
\hline Religiosas & & & & 0,13 & 1,14 & $0,79-1,63$ \\
\hline Ético-morais & & & & $0,53 * *$ & 1,69 & $1,20-2,40$ \\
\hline Psicológicas & & & & $-0,04$ & 0,96 & $0,73-1,28$ \\
\hline Biológicas & & & & $-0,32 *$ & 0,73 & $0,55-0,96$ \\
\hline Psicossociais & & & & $-0,54 * * *$ & 0,59 & $0,44-0,79$ \\
\hline$R^{2}$ & & 0,29 & & & 0,47 & \\
\hline$\Delta R^{2}$ & & & & & 0,18 & \\
\hline
\end{tabular}

Nota. A variável critério é o tipo de preconceito $(0=$ sutil; $1=$ flagrante $)$. Os seminários $(0=$ católicos; $1=$ evangélicos $)$ e o sexo $(0=$ masculino; $1=$ feminino $)$ são variáveis categóricas. $O R=$ odds ratios. $\mathrm{IC}=$ Intervalo de confiança $\operatorname{dos} O R . * p<0,05, * * p<0,01, * * * p<0,001$.

\section{Ancoragem das Crenças sobre a Natureza da Homossexualidade}

A questão que agora iremos responder é: quais são as representações sobre a natureza da homossexualidade desenvolvidas nos seminários católicos e evangélicos estudados? Para responder a essa questão, submetemos os escores das crenças sobre a natureza da homossexualidade a uma ANCOVA. O desenho da análise foi fatorial do tipo 2 (Seminários: católicos versus evangélicos) $\mathrm{X}$ 5(Crenças: religiosas vs. ético-morais vs. psicológicas $v s$. biológicas vs. psicossociais). O primeiro fator é inter-sujeitos e o segundo é intra-sujeitos, controlados por quatro co-variáveis (sexo, idade, tempo de seminário e grau de religiosidade dos participantes). Os resultados mostram um efeito principal significativo do tipo de seminário, $F(1,349)=10,70, p<0,001, \eta^{2}=0,03$. Em geral, os evangélicos $(M=3,77 ; D P=0,66)$ tendem a concordar mais com os itens da escala do que os católicos $(M=3,46 ; D P=0,74)$. Também é significativo o efeito principal das crenças, $F(4$, $1396)=4,57, p<0,001, \eta^{2}=0,02$. A análise dos contrastes indica que a crença na natureza psicológica $(M=4,36 ; D P$ $=1,27)$ é mais forte que a na natureza religiosa $(M=3,84$; $D P=1,66)$ da homossexualidade, $t(349)=6,51, p<0,001$. As crenças religiosas são mais fortes do que as ético-morais $(M=3,71 ; D P=1,61), t(349)=1,81, p<0,07$. As crenças ético-morais são mais fortes do que as psicossociais
$(M=3,10 ; D P=1,34), F(1,349)=4,74, p<0,001$. Não há diferença significativa entre a crença na natureza biológica $(M=3,04 ; D P=1,29)$ e psicossocial da homossexualidade, $F(1,349)=0,53, n s$.

De maior importância, o efeito de interação entre o tipo de seminário e as crenças é significativo, $F(4,1396)=75,73$, $p<0,001, \eta^{2}=0,20$. Esse resultado indica que diferentes representações são praticadas em cada tipo de seminário. A Figura 2 apresenta a representação gráfica dessa interação, e a análise dos contrastes mostra que a única diferença não-significativa entre católicos e evangélicos reside na crença na natureza psicológica da homossexualidade (respectivamente: $M=4,31 ; D P=1,20$ vs. $M=4,41 ; D P=1,33)$, $t(349)=0,37, n s)$. No tocante às demais crenças, os evangélicos acreditam mais do que os católicos nas crenças religiosas $(M=4,75 ; D P=1,27$ vs. $M=2,77 ; D P=1,42), t(349)=11,59$, $p<0,001$, e ético-morais $(M=4,30 ; D P=1,38$ vs. $M=3,00 ; D P=1,59), t(349)=7,53, p<0,001$. Os católicos acreditam mais do que os evangélicos nas crenças biológicas $(M=3,42 ; D P=1,25$ vs. $M=2,72 ; D P=1,23), t(349)=4,45$, $p<0,001$, e psicossociais $(M=3,77 ; D P=1,26$ vs. $M=2,55$; $D P=1,14), t(349)=8,07, p<0,001$. Também é importante salientar que esses resultados mantiverem-se mesmo após controlarmos os efeitos das co-variáveis (sexo, idade, tempo de seminário e religiosidade), os quais não são significativos $(F s<1 ; p s>0,10)$. Estes resultados indicam que as diferenças 


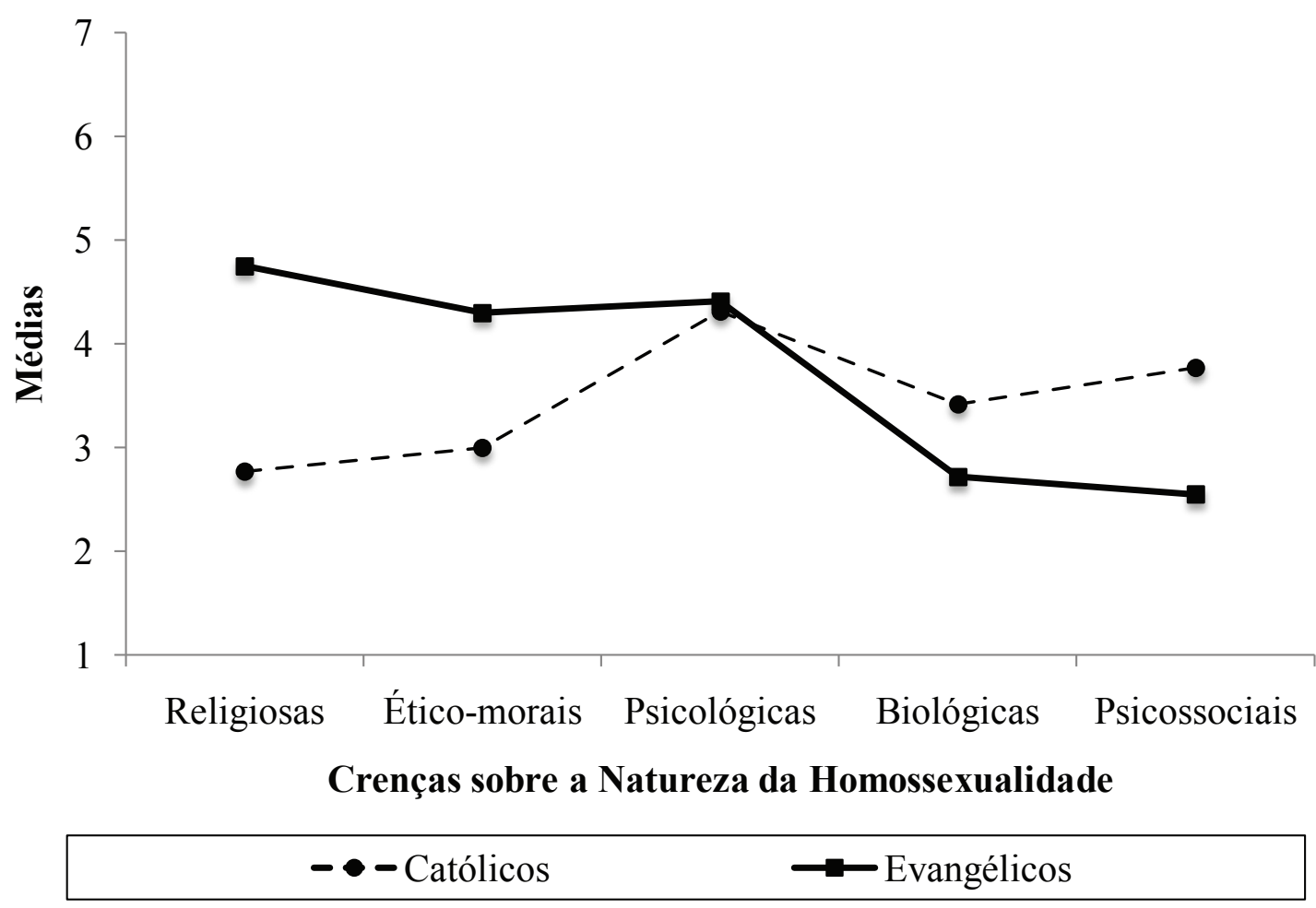

Figura 2. Crenças que caracterizam as representações sobre a natureza da homossexualidade nos seminários católicos e evangélicos.

entre católicos e evangélicos não podem ser explicadas pelas diferenças sócio-demográficas dos seminaristas.

Quando analisamos as crenças comparando-as ao ponto médio da escala (testes $t$ contra 4.00), entre evangélicos, predomina uma representação caracterizada pela crença (médias maiores do que 4,00) na natureza religiosa, ético-moral e psicológica, bem como pela descrença (médias abaixo de $4,00)$ na natureza biológica e psicossocial da homossexualidade: $t_{\text {Religiosas }}(195)=8,88, p<0,001 ; t_{\text {Etico-morais }}(195)=3,76$, $p<0,001 ; t_{\text {Psicológicas }}(195)=4,27, p<0,001 ; t_{\text {Biológicas }}(195)=$ $-14,08, p<0,001 ; t_{\text {Psicossociais }}(195)=-18,09, p<0,001$. Esta representação é diferente da obtida nos seminários católicos, nos quais predomina a crença na natureza psicológica da homossexualidade, a única crença com média maior do que o ponto médio da escala, $t(160)=3,50, p<0,001$. Todas as outras crenças estão abaixo do ponto médio da escala, com forte descrença na natureza religiosa e ético-moral e descrença moderada na natureza biológica e psicossocial da homossexualidade: $t_{\text {Religiosas }}(160)=-11,14, p<0,001$; $t_{\text {Etico-morais }}(160)=-8,34, p<0,001 ; t_{\text {Biológicas }}(160)=-5,52$, $p<0,001 ; t_{\text {Psicossociais }}(160)=-2,18, p<0,05$.

Finalmente, para verificar em que medida as diferenças entre os seminários indicam formas consensuais de representações sociais sobre a natureza da homossexualidade, analisamos homogeneidade das crenças ao nível das religiões (católica vs. evangélica) e ao nível dos seminários. Para realizar esta análise, primeiro calculamos, dento de cada seminário estudado, os desvios-padrão $(D P s)$ da adesão dos participantes às crença sobre a homossexualidade (i.e., quanto menor o $D P$, maior a homogeneidade). Em seguida, calculamos cinco modelos multi-níveis (um para cada tipo de crença), nos quais analisamos a homogeneidade das crenças dentro de cada seminário (nível 1) e entre os tipos de seminários (nível 2). Usando o Hierarchical Linear and Nonlinear Modeling Program (HLM, versão 6.02a, ver Raudenbush, Bryk \& Congdon, 2005) para a estimação das variâncias dos $D P s$, calculamos a correlação intra-classe para cada tipo de crença sobre a natureza da homossexualidade 5 . Os resultados mostraram correlações intra-classe muito fortes, principalmente para as crenças religiosas $(\mathrm{r}=0,90, p<0,001)$, psicossociais $(\mathrm{r}=0,77, p<0,001)$ e ético-morais $(\mathrm{r}=0,66$, $p<0,001$ ), indicando, como era de se esperar, que a homogeneização dessas crenças varia muito mais entre religiões, do que dentro dos seminários de cada tipo de religião. As correlações intra-classe relativas às crenças biológicas $(\mathrm{r}=$ $0,32, p<0,001)$ e psicológicas ( $\mathrm{r}=0,29, p<0,001)$ são apenas moderadas, sugerindo que a explicação da homogeneidade destas crenças não está tão situada ao nível das religiões como nas outras três crenças. Em síntese, estes resultados mostram que o consenso na adesão às crenças religiosas, psicossociais e ético-morais situa-se mais ao nível das religiões, enquanto o consenso na adesão às crenças biológicas e psicológicas situa-se mais ao nível dos seminários.

5 A correlação intra-classe é a proporção da variância de uma variável-critério que é explicada ao nível contextual, i.e., pelas variáveis do nível 2 (ver Raudenbush \& Bryk, 2002). No presente estudo, esse coeficiente indica em que medida a homogeneidade das crenças (i.e., as nossas variáveis-critério) é explicável ao nível das religiões (católica vs. evangélica). 


\section{Discussão}

Os resultados deste estudo respondem às três questões que levantamos na introdução. Primeiramente, mostramos que os grupos religiosos estudados expressam as suas atitudes em relação aos homossexuais em forma de preconceito flagrante ou sutil. Os resultados evidenciaram a presença de preconceito generalizado em relação aos homossexuais, pois, diferentemente de outros estudos (ver Lacerda et al., 2002), não identificamos um grupo de indivíduos não-preconceituosos. Em seguida, mostramos que o tipo de preconceito é diferente em cada tipo de seminário e, sobretudo, depende das crenças sobre a natureza da homossexualidade. Por fim, mostramos que seminários católicos e evangélicos desenvolvem crenças muitos diferentes sobre a homossexualidade. Adicionalmente, verificamos que nem o preconceito nem as crenças estão relacionados com as variáveis sócio-demográficas que diferenciam os dois tipos de seminários estudados. Esse dado é importante porque as diferenças entre católicos e evangélicos não podem ser explicadas por suas características demográficas, mas por diferenças genuínas nas representações que cada grupo elabora sobre a homossexualidade.

Consideramos que esses resultados podem ser compreendidos à luz da teoria das representações sociais, especialmente por as representações resultarem da transformação de conceitos e relações elaborados no âmbito institucional e transformados em saber de senso comum (Moscovici \& Hewstone, 1983). Neste sentido, as explicações para a natureza da homossexualidade produzida no âmbito das instituições religiosas e científicas foram absorvidas pela sociedade e transformadas em teorias de senso comum, as quais denominamos princípios organizadores das representações sobre a natureza da homossexualidade.

As explicações religiosas exprimem a crença, desenvolvida no âmbito da tradição judaico-cristã, de que o comportamento homossexual representa a fraqueza espiritual do indivíduo para resistir às tentações demoníacas, descumprindo o que se julga ser vontade de Deus e revela o distanciamento do modelo de família definido nessa tradição (Greenberg \& Bystryn, 1982). No entanto, essa visão da homossexualidade concorre com outras explicações que foram desenvolvidas no domínio científico. Por exemplo, as ciências médicas difundiram a possibilidade de a homossexualidade ser uma doença fisiológica causada por distúrbios genéticos ou biológicos (Bullough, 1974). Além disso, a psicanálise popularizou uma visão psicologizante da homossexualidade, que é menos moralista, embora considere a homossexualidade como um distúrbio no desenvolvimento da sexualidade (e.g., Freud, 1905/1962). Consideramos que as crenças na natureza biológica ou psicológica exprimem a transformação dessas concepções em saber de senso comum.

Uma interpretação mais recente para a natureza da homossexualidade, desenvolvida a partir dos anos 1960 no seio dos primeiros movimentos gays e posteriormente institucionalizada pela American Psychological Association (1975), concebe a homossexualidade não como uma doença psicológica, negando, portanto a existência de causas psicológicas específicas da homossexualidade e situando-a no quadro das orientações sexuais (e.g., Conselho Federal de Psicologia, 1999) ${ }^{6}$. De fato, esta visão psicossocial da homossexualidade, embora ainda pouco difundida, vinculou-se, nas últimas décadas, a um conjunto de movimentos sociais que lutam pela universalidade dos direitos humanos. Assim, talvez seja a crença nessa possibilidade, associada à idéia da orientação sexual ser cultural e socialmente construída, a base de atitudes menos preconceituosas e o apoio às políticas anti-discriminatórias contra os homossexuais (Camino, 1998).

No entanto, a adesão às crenças psicossociais não foi suficientemente forte para gerar um grupo de seminaristas não-preconceituosos. No caso dos evangélicos, constatamos uma forte rejeição a essas concepções. Entre os católicos, houve uma menor rejeição, mas não o suficiente para constituir uma crença caracterizadora das representações sobre a homossexualidade, uma vez que a média de adesão a elas situaram-se abaixo do ponto médio da escala. Os resultados obtidos diferem do estudo com estudantes universitários realizado por Lacerda et al. (2002), no qual a adesão às crenças psicossociais foi a mais elevada entre todas as demais, fundamentando, subseqüentemente, a formação de um grupo de não-preconceituosos opostos aos preconceituosos flagrantes e aos sutis.

No presente estudo, os seminaristas que formam o grupo dos preconceituosos flagrantes apresentam atitudes mais polarizadas, expressam maior rejeição a relações de proximidade e sentem mais emoções negativas e menos positivas. Os preconceituosos sutis, embora apresentem um grau relativamente moderado de rejeição à proximidade e expressem poucas emoções negativas, não sentem emoções positivas. Como destacado por Lacerda et al. (2002), esse grupo de indivíduos apresenta perfil semelhante àquelas pessoas que alegam não ter nada contra os homossexuais, mas também não têm nada a seu favor. No contexto religioso, esse grupo pode representar pessoas que utilizam o discurso de que não sentem nada de mal em relação ao homossexual, mas não concordam com a prática de relações sexuais com pessoas do mesmo sexo. A tentativa de esconder o preconceito e a hostilidade contra os homossexuais reside na estratégia de dissociar o comportamento homoerótico do autor do comportamento.

A análise dos preditores do tipo de preconceito revelou que os evangélicos exprimem o seu preconceito de forma mais flagrante do que os católicos, que são mais sutis. Entretanto, o que explica a diferença na expressão do preconceito? Analisamos esta questão com base na idéia de que a diferença na forma como católicos e evangélicos exprimem o preconceito deriva de representações sociais distintas sobre a natureza da homossexualidade (Camino \& Pereira, 2000, Lacerda et al., 2002, Pereira et al., 2003). De fato, a relação entre o tipo de preconceito e as crenças sobre a na-

6 A Resolução No 001/99, promulgada pelo Conselho Federal de Psicologia, estabelece normas de atuação para os psicólogos em relação às orientações sexuais. Por considerar que a homossexualidade não é doença, nem distúrbio e nem perversão, a resolução determina que os psicólogos brasileiros não devem participar de eventos e serviços que promovam o tratamento para a homossexualidade. 
tureza da homossexualidade mostra que elas fundamentam o preconceito contra os homossexuais. Em outras palavras, as variações no preconceito dependem das representações sociais sobre a natureza da homossexualidade praticada em cada seminário.

Em síntese, os resultados deste estudo sustentam empiricamente a idéia de que as representações que os grupos sociais constroem sobre a natureza dos outros grupos constituem os fundamentos para os posicionamentos preconceituosos contra grupos minoritários (Lacerda et al., 2002). Neste sentido, qualquer estratégia de intervenção que tenha como objetivo a prevenção ou a redução do preconceito nos seminaristas deverá incidir no tipo de crença sobre a natureza da homossexualidade que são desenvolvidas nos seminários. A ênfase deve ser dada, sobretudo, à descrença nos fundamentos moralistas e na crença numa natureza psicossocial da homossexualidade. No entanto, o efeito das crenças altera a forma como os seminaristas expressam o preconceito, uma vez que o suporte a atitudes preconceituosas é generalizado nos seminários.

Embora a investigação efetuada apresente evidência empírica suficientemente forte para a sustentação da hipótese de que as representações sobre a natureza da homossexualidade estão na base do preconceito, o estudo realizado apresenta algumas limitações importantes. Por exemplo, os resultados que encontramos não devem ser vistos como tendências gerais ocorridas nos seminários brasileiros, uma vez que este estudo não foi realizado com uma amostra representativa dos seminários católicos e evangélicos em atuação no Brasil. No entanto, a limitação mais importante refere-se ao método correlacional adotado. Ao conduzirmos as análises, pressupomos que as atitudes preconceituosas estão ancoradas nas representações. Neste sentido, propusemos um modelo de análise que parte das representações sociais para o preconceito. Dada a natureza correlacional do estudo, não podemos afirmar empiricamente que o processo ocorre nesse sentido ou no seu inverso. Novas investigações que tornem experimentalmente salientes as representações da homossexualidade e observem o seu impacto no preconceito podem mostrar de forma mais precisa, e sem margem para interpretações alternativas, a direção das relações propostas. Além disso, é importante que estudos experimentais sejam realizados para analisar se o grupo-alvo do preconceito (i.e., homossexuais masculinos vs. femininos) funciona como um moderador do efeito das crenças no preconceito contra os homossexuais.

Apesar destas limitações, consideramos que a direção das relações propostas está teoricamente consistente com a idéia de que as representações estão na base das atitudes e dos comportamentos dos atores sociais (Moscovici, 1969/1976), pois modelam o contexto e justificam as atitudes e comportamentos. Em conclusão, o estudo que realizamos mostrou que um tipo específico de representações sociais (i.e., as crenças sobre a natureza da homossexualidade), analisada no contexto das relações intergrupais, pode ser o fator preponderante na determinação das tensões entre os grupos, nomeadamente o tipo de preconceito praticado por seminaristas católicos e evangélicos contra os homossexuais.

\section{Referências}

Aldenderfer, M. S., \& Blashfield, R. K. (1984). Cluster Analysis. Thousand Oaks: Sage.

American Psychological Association. (1975). Minutes of the council of representatives. American Psychologist, 30(6), 620-651.

Bastian, B., \& Haslam, N. (2006). Psychological essentialism and stereotype endorsement. Journal of Experimental Social Psychology, 42(2), 228-235.

Bullough, V. L. (1974). Homosexuality and the medical model. Journal of Homosexuality, 1(1), 99-110.

Camino, L. (1998). Direitos humanos e psicologia. Em Comissão de Direitos Humanos do Conselho Federal de Psicologia (Ed.), Psicologia, ética e direitos humanos (pp. 39-63). Brasília: Conselho Federal de Psicologia.

Camino, L., \& Pereira, C. (2000). O papel da psicologia na construção dos direitos humanos: Análise das teorias e práticas psicológicas na discriminação ao homossexualismo. Perfil, 13(13), 49-69.

Conselho Federal de Psicologia. (1999). Resolução número 1/1999: Normas de atuação para os psicólogos em relação à questão da orientação sexual. Brasília: Conselho Federal de Psicologia.

Crandall, C. S., Eshleman, A., \& O'Brien, L. T. (2002). Social norms and the expression and suppression of prejudice: The struggle for internalization. Journal of Personality and Social Psychology, 82(3), 359-378.

Crawford, I., McLeod, A., Zamboni, B. D., \& Jordan, M. B. (1999). Psychologists' attitudes toward gay and lesbian parenting. The American Psychological Association, 4, 394-401.

Deschamps, J. C., Vala, J., Marinho, C., Lopes, R. C., \& Cabecinhas, R. (2005). Intergroup relations, racism and attribution of natural and cultural traits. Psicología Política, 30(1), 27-39.

Doise, W., Clémence, A., \& Lorenzi-Cioldi, F. (1993). The quantitative analysis of social representations. Hempel Hempstead: Harvester Wheatsheaf.

Faria, M. R.G. V. de, Leite, T. V., Torres, A. R. R., \& Bittar, M. M.. (2006). Influência dos ideais democráticos na discriminação contra portadores do HIV. Revista de Psicologia da UnC, Concordia - SC, 1,1-11.

Frank, D. J., \& McEneaney, E. H. (1999). The individualization of society and the liberalization of states policies on same-sex sexual relations, 1984-1995. Social Forces, 77(3), 911-944.

Freud, S. (1905/1962). Three essays on the theory of sexuality translation. Em J. Strachey (Ed.), The standard edition of the complete psychological works of Sigmund Freud (Vol. 7, pp. 136-244). London: Hogarth.

Gaertner, S. L., \& Dovidio, J. F. (1986). The aversive form of racism. Em J. F. Dovidio \& S. L. Gaertner (Eds.), Prejudice, discrimination, and racism (pp. 61-89). San Diego: Academic Press.

Greenberg, D. F., \& Bystryn, M. (1982). Christian intolerance of homosexuality. American Journal of Sociology, 88, 515-548.

Haddock, G., Zanna, M. P., \& Esses, V. M. (1993). Assessing the structure of prejudicial attitudes: The case of attitudes toward homosexuals. Journal of Personality and Social Psychology, 65 (6), 1105-1118.

Haslam, N., Bastian, B., \& Bissett, M. (2004). Essentialist beliefs about personality and their implications. Personality and Social Psychology Bulletin, 30(12), 1661-1673. 
Haslam, N., \& Levy, S. R. (2006). Essentialist beliefs about homosexuality: Structure and implications for prejudice. Personality and Social Psychology Bulletin, 32(4), 471-485.

Haslam, N., Rothschild, L., \& Ernst, D. (2000). Essentialist beliefs about social categories. British Journal of Social Psychology, 39(1), 113-127.

Haslam, N., Rothschild, L., \& Ernst, D. (2002). Are essentialist beliefs associated with prejudice? British Journal of Social Psychology, 41(1), 87.

Hegarty, P. (2002). "It's not a choice, it's the way we're built:" Symbolic beliefs about sexual orientation in the United States and in Britain. Journal of Community and Applied Social Psychology, 12(1), 1-14.

Hegarty, P., \& Pratto, F. (2001). Sexual orientation beliefs: Their relationship to antigay attitudes and biological determinist arguments. Journal of Homosexuality, 41(1), 121-135.

Jayaratne, T. E., Ybarra, O., Sheldon, J. P., Brown, T. N., Feldbaum, M., \& Pfeffer, C. A. (2006). White Americans' genetic lay theories of race differences and sexual orientation: Their relationship with prejudice toward blacks, and gay men and lesbians. Group Processes \& Intergroup Relations, 9(1), 77-94.

Jost, J. T. (1992). Social representations and the philosophy of science: Belief in ontological realism as objectification. Papers on Social Representations, 1(2-3), 116-124.

Katz, I., \& Hass, R. G. (1988). Racial ambivalence and American value conflict: Correlational and priming studies of dual cognitive structures. Journal of Personality and Social Psychology, 55(6), 893-905.

Lacerda, M., Pereira, C., \& Camino, L. (2002). Um estudo sobre as formas de preconceito contra homossexuais na perspectiva das representações sociais. Psicologia: Reflexão e Crítica, 15(1), 165-178.

Leyens, J.-P., Paladino, P. M., Rodriguez-Torres, R., Vaes, J., Demoulin, S., Rodriguez-Perez, A., \& Gaunt, R. (2000). The emotional side of prejudice: The attribution of secondary emotions to ingroups and outgroups. Personality and Social Psychology Review, 4(2), 186-197.

McConahay, J. B., Hardee, B. B., \& Batts, V. (1981). Has racism declined in America? It depends on who is asking and what is asked. Journal of Conflict Resolution, 25(4), 563-579.

Medin, D., \& Ortony, A. (1989). Psychological essentialism. Em S. Vosniadou \& A. Ortony (Eds.), Similarity and analogical reasoning (pp. 183-196). New York: Cambridge Academic Press.

Meertens, R. W., \& Pettigrew, T. F. (1997). Is subtle prejudice really prejudice. Public Opinion Quarterly, 61(1), 54-71.

Melton, G. B. (1989). Public policy and private prejudice: Psychology and law on gay rights. American Psychologist, 44(6), 933-940.

Moradi, B., van den Berg, J. J., \& Epting, F. R. (2006). Intrapersonal and interpersonal manifestations of antilesbian and gay prejudice: An application of personal construct theory. Journal of Counseling Psychology of Men \& Masculinity, 53(1), 57-66.

Moscovici, S. (1969/1976). La psychanalyse, son image et son public. Paris: PUF.

Moscovici, S., \& Hewstone, M. (1983). Social representations and social explanations: From the "naive" to the "amateur" scientist. Em M. Hewstone (Ed.), Attribution theory: Social and functional extensions (pp. 98-125). Oxford: Blackwell.
Moscovici, S., \& Pérez, J. A. (1997). Prejudice and social representations. Papers on Social Representations, 6(1), 27-36.

Pereira, C., Torres, A. R. R., \& Pereira, A. (2003). Preconceito contra prostitutas e representações sociais da prostituição em estudantes de teologia católicos e evangélicos. Em M. E. Lima \& M. E. Pereira (Eds.), Estereótipos, preconceito e discriminação: perspectivas teóricas e metodológicas (pp. 209-234). Salvador: EDUFBA.

Pereira, C., Vala, J., \& Leyens, J-P. (2009). From infra-humanization to discrimination: The mediation of symbolic threat needs egalitarian norms. Journal of Experimental Social Psychology, 45, 336-344.

Pérez, J. A., Moscovici, S., \& Chulvi, B. (2002). Natura y cultura como principio de clasificación social. Anclaje de representaciones sociales sobre minorías étnicas. Revista de Psicología Social, 17(1), 51-67.

Pettigrew, T. F., Jackson, J. S., Brika, J. B., Lemaine, G., Meertens, R. W., Wagner, U., \& Zick, A. (1998). Outgroup prejudice in Western Europe. European Review of Social Psychology, 8, 241-273.

Pettigrew, T. F., \& Meertens, R. W. (1995). Subtle and blatant prejudice in Western Europe. European Journal of Social Psychology, 25(1), 57-75.

Pettigrew, T. F., \& Meertens, R. W. (2001). In defense of the subtle prejudice concept: A retort. European Journal of Social Psychology, 31(3), 299-309.

Raudenbush, S., \& Bryk, A. (2002). Hierarchical linear models: Applications and data analysis methods. Thousand Oaks: Sage.

Raudenbush, S., Bryk, A., \& Congdon, R. (2005). HLM 6.02a: hierarchical linear and nonlinear modeling. Lincolnwood: Scientific Software International.

Rothbart, M., \& Taylor, M. (1992). Category labels and social reality: Do we view social categories as natural kinds? Em G. Semin \& K. Fiedler (Eds.), Language, interaction and social cognition (pp. 11-36). Newbury Park: Sage.

Sears, D. O., \& Henry, P. J. (2003). The origins of symbolic racism. Journal of Personality and Social Psychology, 85(2), 259-275.

Torres, A. R. R., \& Faria, M. R. G. V. de (2008). Creencia en el Mundo Justo y Prejuicio: homosexuales portadores de VIH/ SID. Interamerican Journal of Psychology, 42(3), 570-579.

Vala, J., Brito, R., \& Lopes, D. (1999). Expressões dos racismos em Portugal. Lisboa: Instituto de Ciências Sociais.

Vala, J., Lopes, D., Lima, M. E., \& Brito, R. (2002). Cultural differences and heteroethnicization in Portugal: The perceptions of White and Black people. Portuguese Journal of Social Science, 1(2), 111-128.

Ward, J. H. (1963). Hierarchical grouping to optimize an objective function. Journal of American Statistical Association, 58, 236-244.

Recebido em 09.06.2009

Primeira decisão editorial em 13.10.2009

Versão final em 19.10.2009

Aceito em 22.10.2009 